angle of the retracted lower eyelid. It is in the gutter thus formed that one places the lower eyelid, freed by an incision, oblique below and inside, and slightly curvilinear at its lower extremity.

Sutures.-In order to avoid all retraction, before fixing the points of suture, we place a provisional prothesis in the orbital cavity.

The two advantages of the, operation described over that of Snellen are the following:

1. Better nutrition of the flap, of which the base may be larger and which is not nipped or rendered anæmic by the button-hole which Snellen makes near the external angle.

2. The conjunctival and cutaneous suturing is rendered much easier by the liberation of the lower eyelid.

We have had occasion to employ the operation described upon two wounded soldiers in the Belgian ophthalmological service of No. 30 Complementary Hospital at Rennes.

First case.-D.- infantryman. Penetrating wound of the eye by rifle bullet. The bullet must have entered through the cornea (there was no lesion of the skin of the eyelids) and emerged behind the ear. Enucleation the same day in a hospital at the front. We saw the patient 37 days after enucleation. The lower cul-de-sac could not be said to exist ; the conjunctiva was retracted and cicatricial, and the introduction of an artificial eye was impossible. The operation, which I have described, made the wearing of a prothesis very easy (see Fig. 4).

Second case.-S. M., aviation mechanician, was wounded by a fragment of a bomb from an aeroplane. The eye was enucleated in a hospital at the front.

On arrival at Rennes we found.-A cicatricial band of the upper eyelid, $1 \mathrm{~cm}$. from the internal angle, and ectropion of the outer part of the upper eyelid. The lower cul-de-sac was completely bridled by cicatricial bands, drawing the lower eyelid towards the depths of the orbit, the cul-de-sac being completely absent.

In order to correct the ectropion, freshening and suture of the upper eyelid, and operation according to the technique described above. After this operation the wearing of an artificial eye became quite easy.

S. S.

\title{
ANNOTATIONS
}

\section{A Representative Council of British Ophthalmologists}

A meeting of ophthalmic surgeons was held on May, 2 last at the house of the Royal Society of Medicine, for the purpose of forming a representative council empowered to take action in matters of 
ophthalmological interest in connection with public aftairs. $\mathrm{Mr}$. E.Treacher Collins, president of the Ophthalmological Society of the United Kingdom, was voted to the chair. The resolution that such a council (see these columns April, 1918, p. 230) be formed was proposed by Sir Anderson Critchett, Bt., C.V.O., who said it would meet a definite need, would tend to weld the elements of ophthalmology more closely together, and would make for the public welfare. Mr. F. Richardson Cross seconded the resolution, remarking that governments and governing bodies required expert advice in order to be efficient, and that the best experts were those who enjoyed the confidence of their colleagues. Owing to the amalgamation of the journals devoted to ophthalmology, and to the representation on the Ophthalmological Society of the various similar bodies in the kingdom, the profession was now well organized, and could present a powerful front on all questions which specially concerned it. As instances he mentioned ophthalmia neonatorum, Army and Navy visual standards, industrial lighting, enquiries concerning the blind, compensation payable according to degrees of visual disability, and so forth. Mr. J. B. Lawford, in supporting the resolution, said that the days were rapidly passing when we could afiord to ignore scientific discoveries and the new methods based upon them, and he believed that in the future more attention would be paid to the views of representative bodies and less to the opinions of individuals, however eminent. The State was assuming more and more the rôle of parent, and, like other parents, would be the better for sound advice. He would like to see ophthalmology made a compulsory subject in the medical curriculum, a matter in which we were much behind other civilized countries. At present a man who obtained the minimal qualifying medical diploma could at once take up the practice of ophthalmology, and if the council did nothing beyond insisting that it was not taken up without special training, it would fully justify its formation. Speeches in support were made by Mr. J. Gray Clegg, Sir George Berry, and Mr. George Mackay, and the resolution was carried unanimously. The meeting further decided that the council should consist of all the past and present presidents of the Ophthalmological Society of the United Kingdom and of the Section of Ophthalmology of the Royal Society of Medicine (permanent members), of four members nominated annually by the councils of each of those societies, and of one representative, also elected annually, by the Oxford Ophthalmological Congress.

\section{Medical Certificates}

A circular dated March 12, 1918, dealing with medical certificates in connection with men who appear before National Service Medical 